\title{
EXTENSION NEEDS OF GREENHOUSE GROWERS IN HALABJA DISTRICT OF SULAIMANIA GOVERNORATE AND ITS RELATIONSHIP WITH SOME FACTORS
}

(Received: 26.8.2014)

\author{
H. S. Murad, A.A. H. Al-Doski and T. H. Laiq* \\ Faculty of Agriculture, University of Duhok and * Polytechnical, Halabja
}

\begin{abstract}
The main objective of the present study was to determine the extension needs of greenhouse growers in the district of Halabja - Sulaimania Governorate in general. The research involved respondents (72) selected randomly. A questionnaire was used to collect the data. To analyze the research data, weight percentile, the arithmetic mean, and the standard deviation were used. Moreover, the equation of boric was developed to measure the extension needs. The results showed that there is a high or medium need to training specially in some items. The findings also showed that there is a significant correlation between extension needs of the respondents and each of the level of education, and experience in protected agriculture previously, and no significant correlation between the training extension needs and (age, sex, number of years of growing vegetables, previous training and using of information sources).
\end{abstract}

Key words: extension needs, greenhouse growers, Halabja, relationship with some factors.

الاحتياجات الارشادية لمزارعي البيوت البلاستيكية في قضاء حلبجة بمحافظة السليمانية وعلاقتها ببعض العوامل

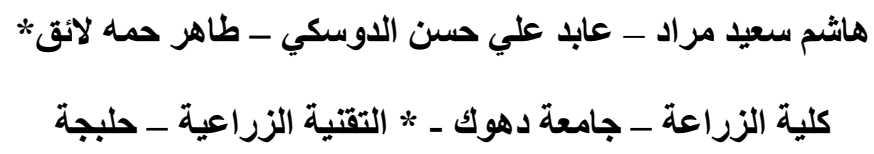

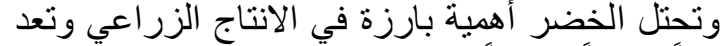

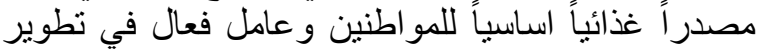

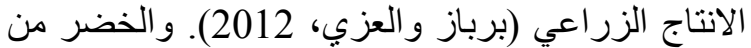

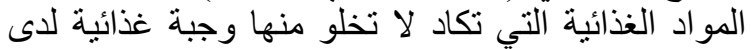

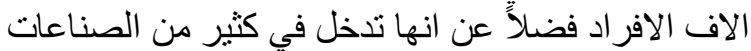

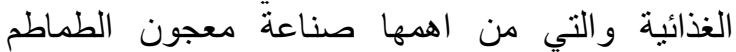

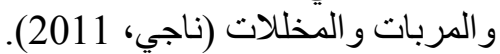

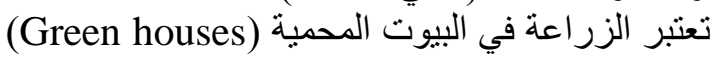
احد اهم الاساليب الحديثة في المجال الزراعي والتي

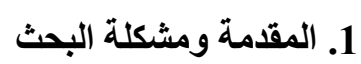

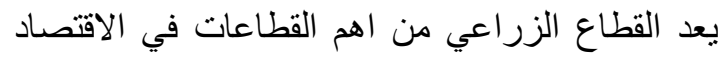

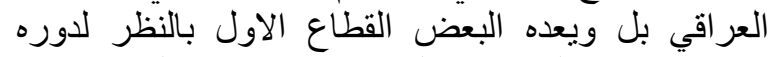

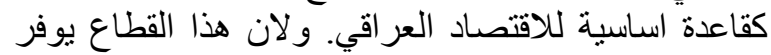

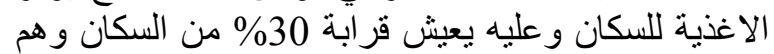

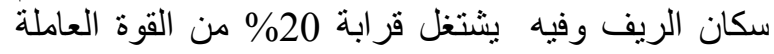

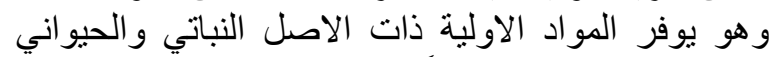

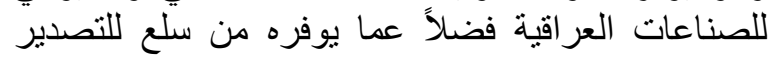

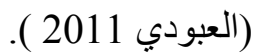


ولأجل تحقيق الهذف الثالث للبحث تم صياغة الفرضيات البحثية الآتية:

1- لا توجد علاقة ارتباط معنوية بين مسنوى الآنية الاحتياجات

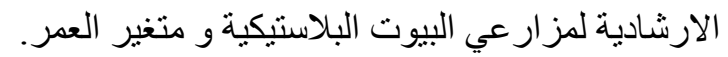

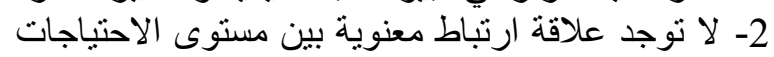

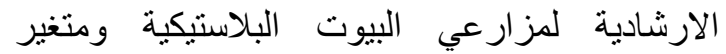

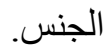

3- لا نوجد علاقة ارتباط معنوية بين مسنوى الاحتياجات

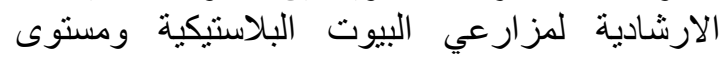

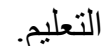

4- لا نوجد علاقة ارتباط معنوية بين مستوى الاحتياجات

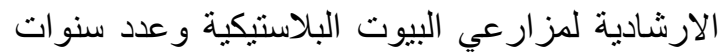
زر اعة الخضروات.

5- لا توجد علاقة ارتباط معنوية بين مستوى الاحتياجات

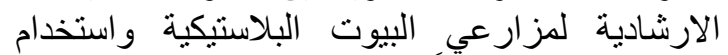
الز الزر اعة المحمية سابقاً.

6- لا توجد علاقة ارتباط معنوية بين مستوى الاحتياجات

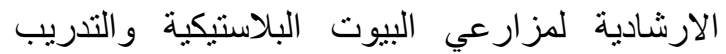
السابق. - (الارن 7- لا توجد علاقة ارتباط معنوية بين مستوى الاحتياجات

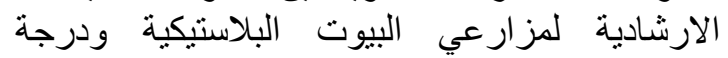
استخدام مصادر المعلومات الزر اعية.

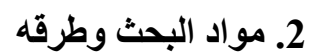

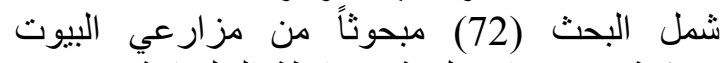

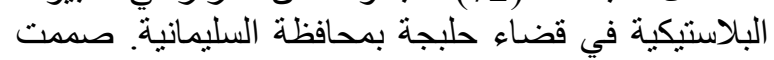
استمارة استبيان خاصة بهاء بها تضمن الجزء التهاء الاول منها

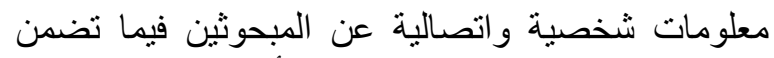

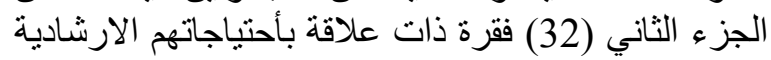

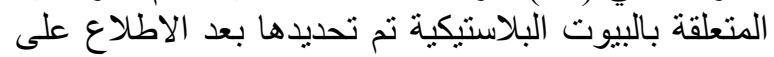

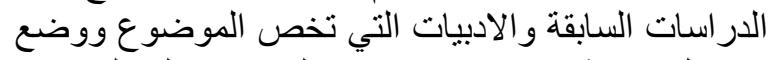

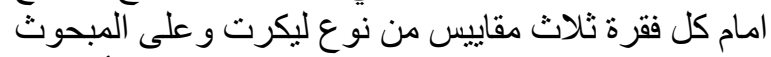
بعد قراءة الفقرة ان يؤشر على ألى احد البدائل الخمسة أمام كل لئل

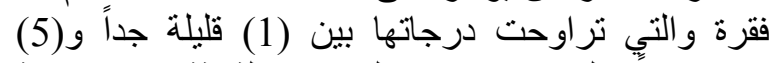

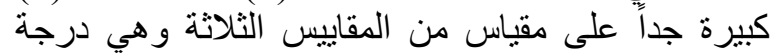

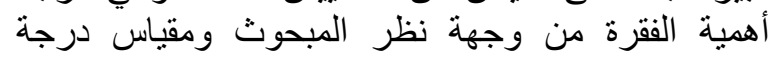

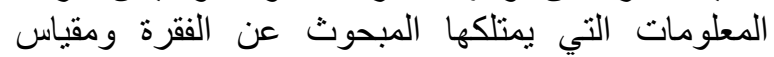

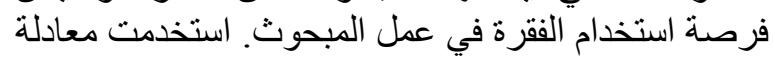

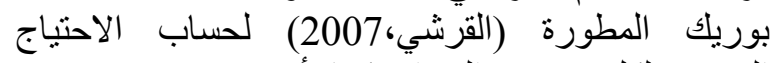
التدريبي لكل فقرة من الفقرات كما يأتي: (2007) $T n=\frac{\{((I-K) * I)+((I-O) * I)\}}{2}$

$$
\text { حيث أن: }
$$

Tn = I

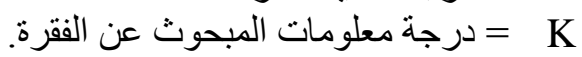
و = O

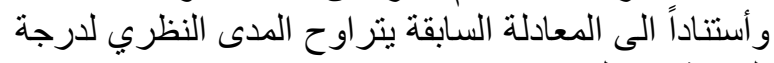

الحاجة في كل فقرة بين (+20) و (-4).
تساعد في زيادة الانتاج وفي التتمبة الزراعية. ويعد

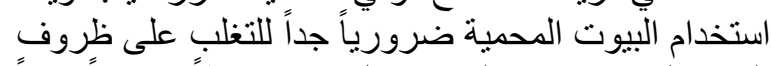

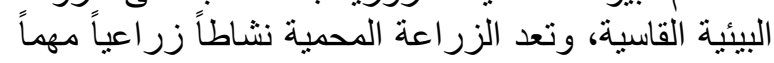

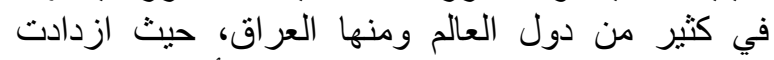

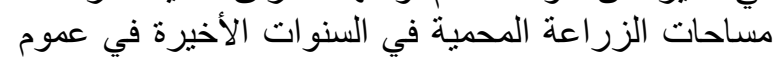

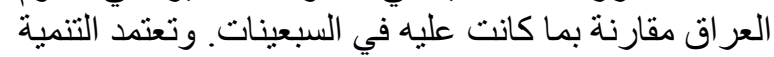

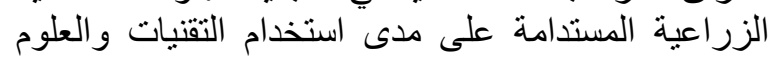

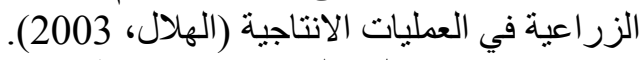

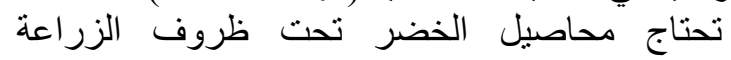
المحمية إلى تقانات عدة لنجاح زراعنها في في منل هذه

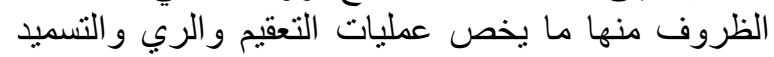

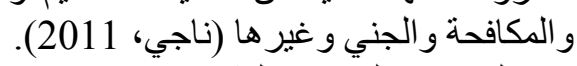

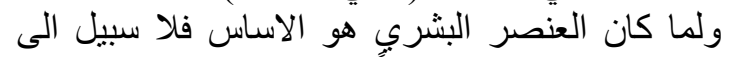

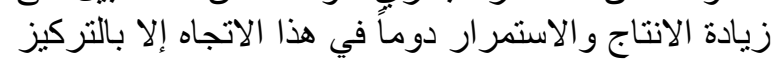

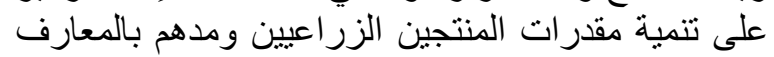

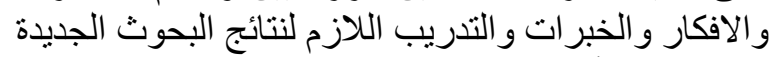

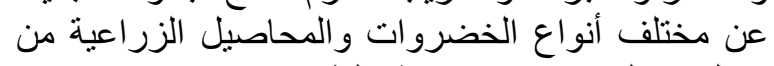

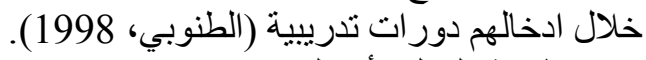

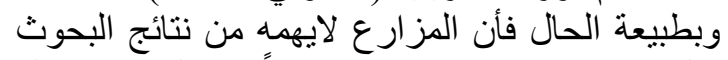

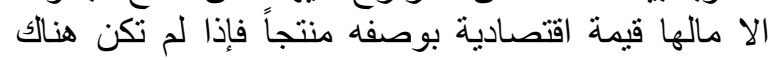

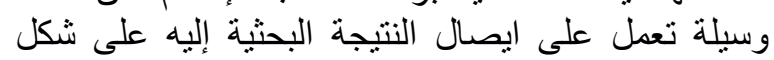

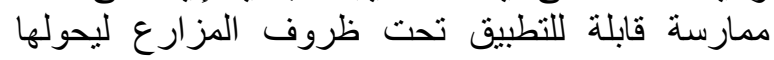
بدوره الى قيمة اقتصادية فإن جهود العاملين الارشناديين قد فئد ضاعت سدى (سداد، 1993).

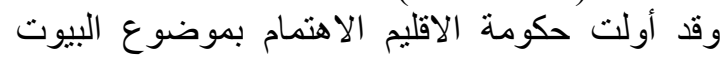

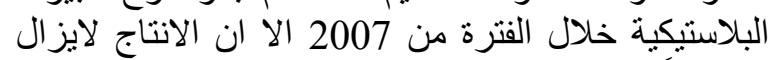

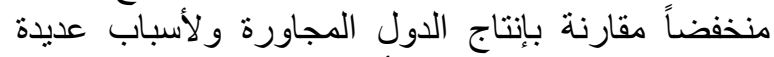

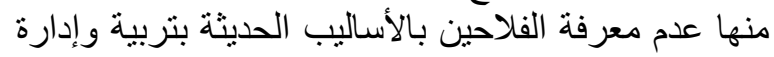

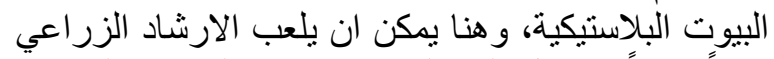

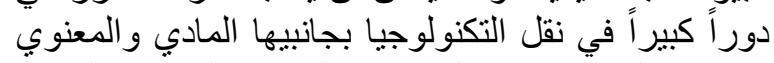

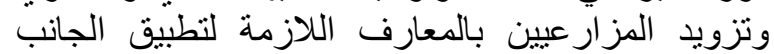

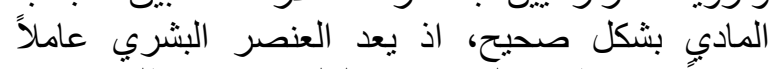

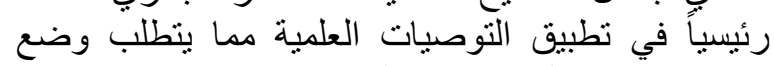

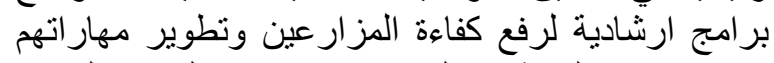

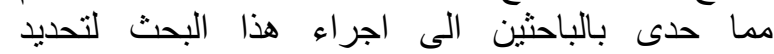

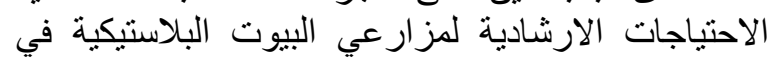

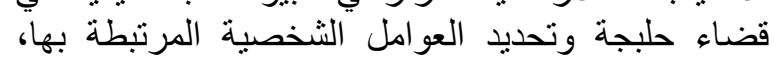
وبشكل اكثر دقة يهدف البحثث الحالي الى ما لإيلي:

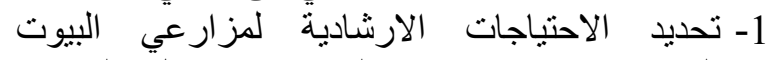

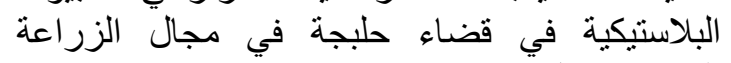

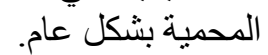
2- ترتيب فقرات مقياس الاحتياجات الارشادية لمزارعي

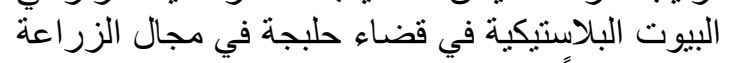
المحمية وفقاً للاهمية. 3- تحديد العلاقة الارنباطية بين مستوى الاحتئة الإنيات

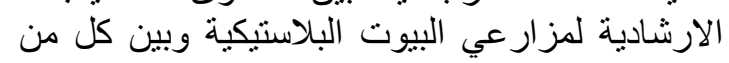

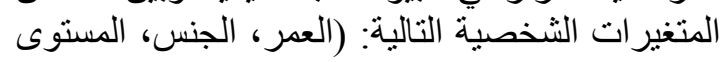

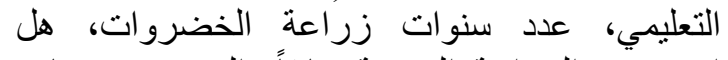
استخدمت الزراعة المحمية سابقاً، التدريب، مصنادرات الترل

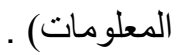




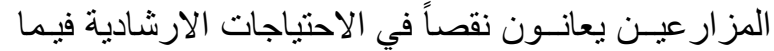

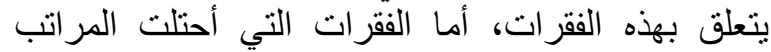

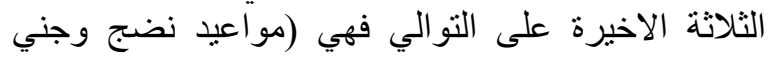

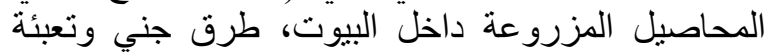

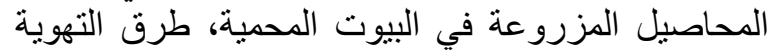

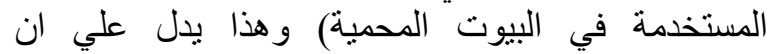
المزارعين يحتاجون بدرجة القل الى الى التدريب في هذي لئه

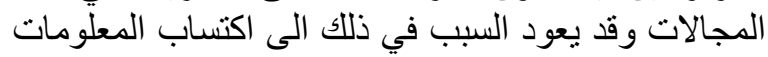

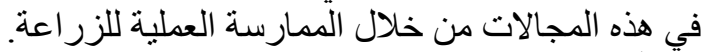

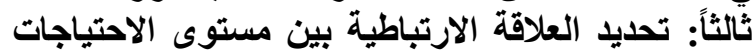

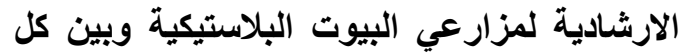

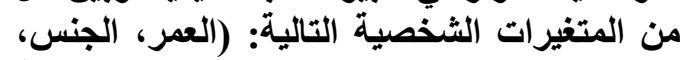

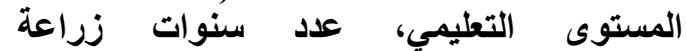

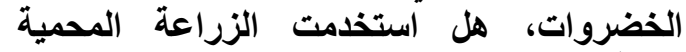

سابقاً، التدريب، مصادر المعلومات) جدول المبل (3).

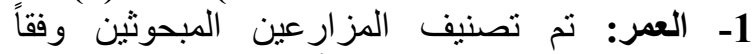

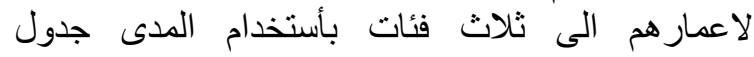

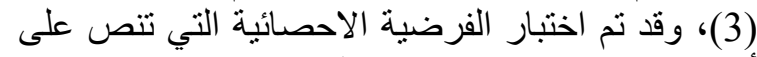

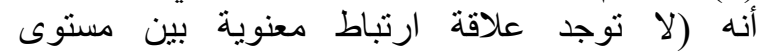

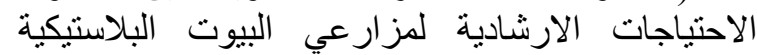

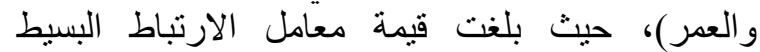
بيرسون (r) المحسوبة (0.134) و هي أقل من من القية القيمة

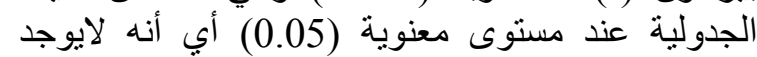

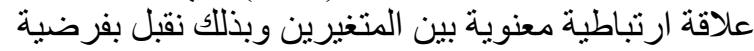

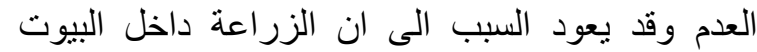

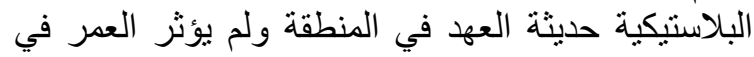
ذللك.

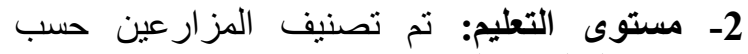
مستواهم التعليمي اللى ست فئات كما هو موضنح في فئ

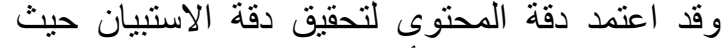

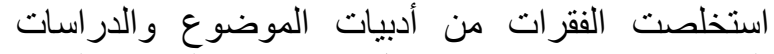
السابقة، كما تم قياس ثبات كل مقياس من المقايس الثنلاثة (الأهمية - المعلومات - الاستخدام) بطريقة التجزئة التئة

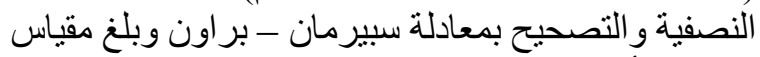
الثبات الأهمية 0,811 وثبات مقياس المعلومات وثبات مقياس فرصة الأستخدام 0,921 و وهي معات معاملات ثبات عالية. وقد استخدمت المنتوسطات الحسابية لايجاد

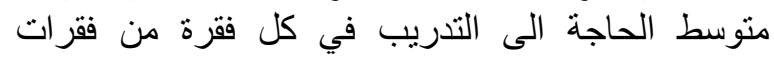
المقياس لجميع المبحوثين بشكل النئ عام. كما استخدم معامل

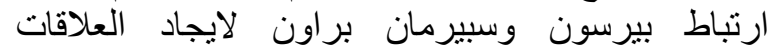

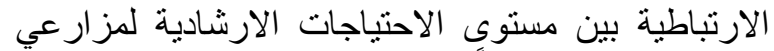
البيوت البلاستيكية وفقاً لمتغير الات البحثن.

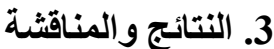

اولاً: تحديد الاحتباجات الارشادية لمزارعي البيوت

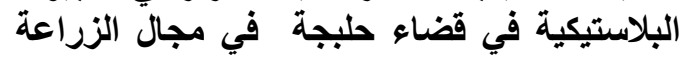

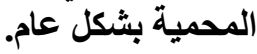

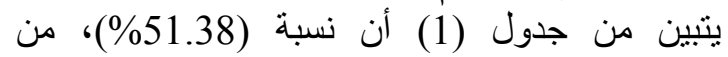

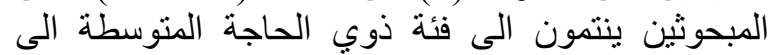

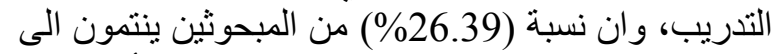

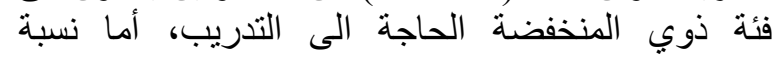

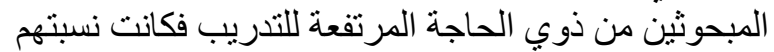
(22.23\%)، وهذا يعني ان النسبة الاكبر من المبحة المبحوثين

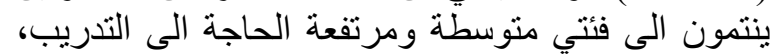

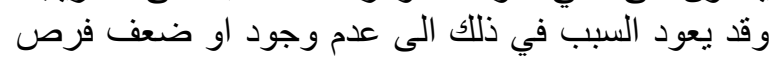

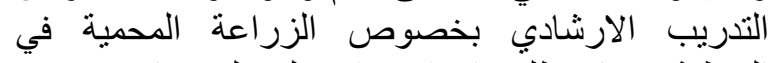

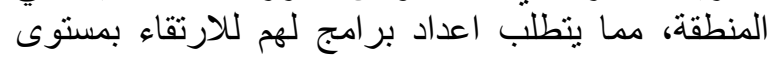
مهار اتهم في زر اعة و ادارة البيوت البلاستيكية.

جدول رقم (1): توزيع المزارعين المبحوثين وفقاً لاحتياجاتهم الارشادية.

\begin{tabular}{|c|c|c|c|c|c|}
\hline الاتحراف المعياري & المتوسط الحسابي & النسبة المئوية & 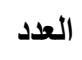 & الفئات & $ت$ \\
\hline \multirow{4}{*}{100.073} & \multirow{4}{*}{189.458} & 26.39 & 19 & حاجة منخفضة 134 فأقلّل & 1 \\
\hline & & 51.38 & 37 & حاجة منوسطة 135-247 & 2 \\
\hline & & 22.23 & 16 & حاجة مرتفعة 275 فأكثر & 3 \\
\hline & & $\% 100$ & 72 & المجموع & \\
\hline
\end{tabular}

جدول (3) ويتبين أرتفاع نسبة الذين يقروؤن ويكتبون

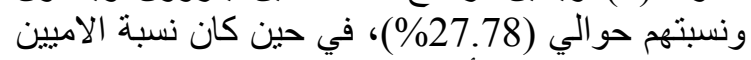

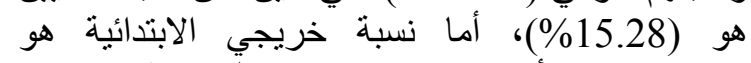

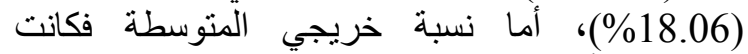

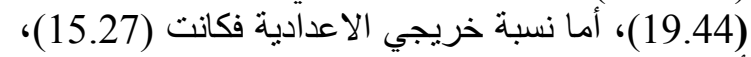

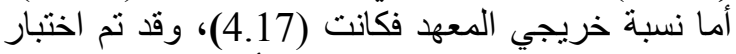
الفرضية الاحصائية التي تنص على أنه (لا توجد علاقدة
ثانياً: ترتيب فقرات مقياس الاحتياجات الارشادية

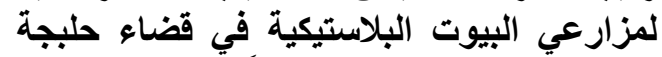

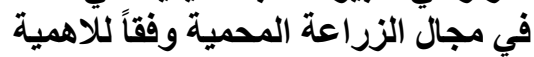

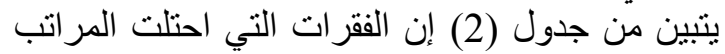

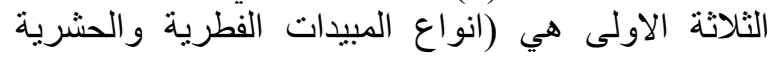

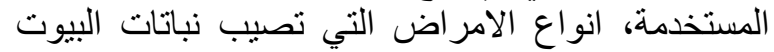
المحمية، اختيار موقع البيوت المحمية) و هذا يدل على ان ان النات النية 
جدول رقم (2): ترتيب فقرات الحاجة للتدريب في مجال الزراعة المحمية.

\begin{tabular}{|c|c|c|c|c|}
\hline الرتبة & الوزن المئوي & المتوسط الحسابي & الفقرات & $ت$ \\
\hline 1 & 47.220 & 9.444 & انواع المبيدات الفطرية و الحشرية المستخدمة. & .1 \\
\hline 2 & 40.240 & 8.048 & انواع الامر اض التي تصيب نباتات البيوت المحمية. & .2 \\
\hline 3 & 36.975 & 7.395 & اختبار موقع البيوت المحمية. & .3 \\
\hline 4 & 36.315 & 7.263 & الدكافحة و الوقاية داخل البيوت المحمية. & .4 \\
\hline 5 & 36.250 & 7.250 & طرق تعقيم التربة في البيت البلاستيكي. & .5 \\
\hline 6 & 35.520 & 7.104 & تسليف المزار عين. & .6 \\
\hline 7 & 34.270 & 6.854 & مصدر المبيدات المستعملة في المكافحة الآفات. & .7 \\
\hline 8 & 33.400 & 6.680 & اختيار الاصناف المقاومة للامر اض و الحشرات. & .8 \\
\hline 9 & 33.330 & 6.666 & اختبار الاصناف ذات الانتاجية العالية. & .9 \\
\hline 10 & 31.805 & 6.361 & اختيار الارض المناسبة للزر اعة المحمية. & .10 \\
\hline 11 & 30.725 & 6.145 & اتجاه البيوت المحمية عند انشاؤها. & .11 \\
\hline 12 & 30.690 & 6.138 & الثتلات تهيئة اللازمة للزر اعة في البيوت المحمية. & .12 \\
\hline 13 & 30.310 & 6.062 & مو اعيد زر اعة الثتلات في البيت البلاسنيكي (حسب المحصول) & .13 \\
\hline 14 & 29.405 & 5.881 & كميات الاسمدة المستخدمة. & .14 \\
\hline 15 & 29.235 & 5.847 & طرق حماية البيوت البلاستيكية من الرياح القوية. & .15 \\
\hline 16 & 29.165 & 5.833 & مو اصفات التربة المستخدمة في البيوت المحمية. & .16 \\
\hline 17 & 28.645 & 5.729 & 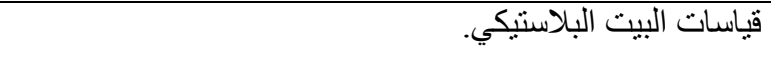 & .17 \\
\hline 18 & 28.540 & 5.708 & خذمة الشتلات بعد الزر اعة. & .18 \\
\hline 19 & 28.470 & 5.694 & مو اعيد اضافة الاسمدة الكيمياوية. & .19 \\
\hline 20 & 28.125 & 5.625 & طرق الري المستخدمة في البيوت المحمية. & .20 \\
\hline 21 & 27.985 & 5.597 & و الرطوبا الزر اعة التهوية. & .21 \\
\hline 22 & 27.500 & 5.500 & عمر الغطاء البلاستيكي. & .22 \\
\hline 23 & 27.220 & 5.444 & اجز اء البيت البلاستيكي من حيث نو عية وسمك البلاستيك. & .23 \\
\hline 24 & 27.045 & 5.409 & طرق تركيب الغطاء البلاستيكي. & .24 \\
\hline 25 & 26.940 & 5.388 & انواع البيوت المحمية. & .25 \\
\hline 26 & 26.490 & 5.298 & طرق التدفئة المستخدمة في البيوت المحمية. & .26 \\
\hline 27 & 26.385 & 5.277 & مسافات الزر اعة في البيت البلاستيكي (حسب المحصول). & .27 \\
\hline 28 & 26.280 & 5.256 & انواع البلاستيك المستخدم في تغطية البيوت. & .28 \\
\hline 29 & 23.330 & 4.666 & مواصفات الهيكل المعدني للبيت البلاستيكي. & .29 \\
\hline 30 & 21.215 & 4.243 & مو اعبد نضج وجني المحاصيل المزروعة داخل البيوت. & .30 \\
\hline 31 & 18.125 & 3.625 & طرق جني وتعبئة المحاصيل المزروعة في البيوت المحمية. & .31 \\
\hline 32 & 10.065 & 2.013 & طرق التهوية المستخذمة في البيوت المحمية. & .32 \\
\hline
\end{tabular}




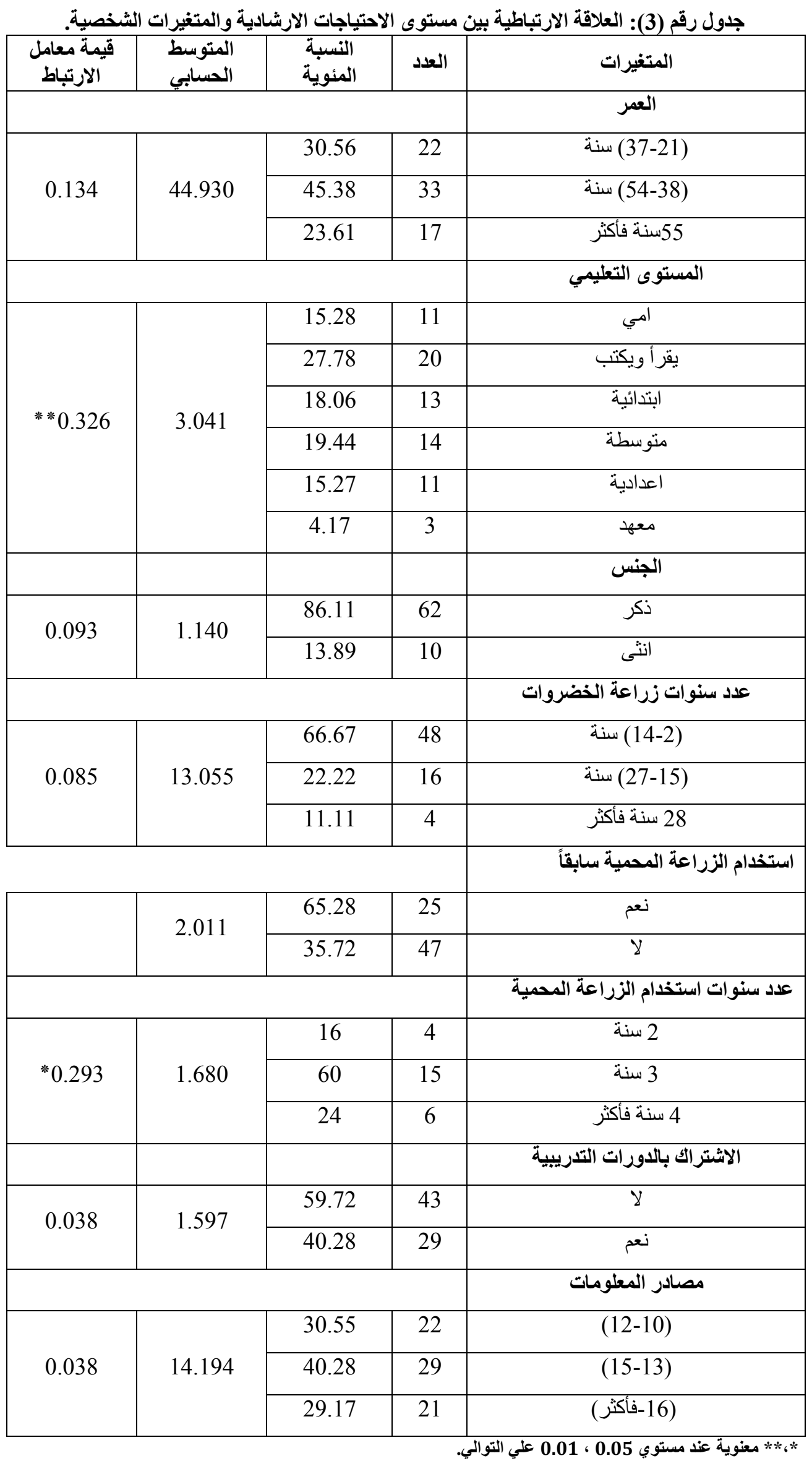


الزراعة المحمية وكانت نسبتهم (24\%)، وقد تم اختبار

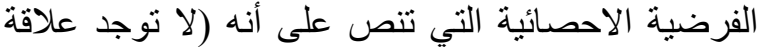
ارتباط معنوية بين مستوى الاحتية لإنياجات الارشادية

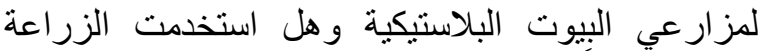

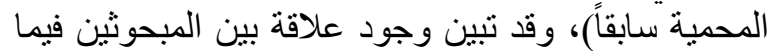

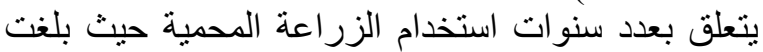

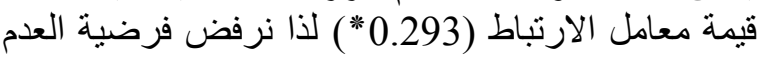

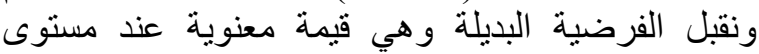

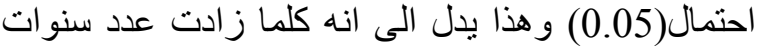

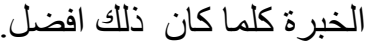

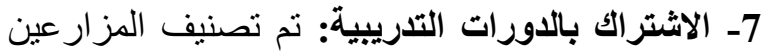

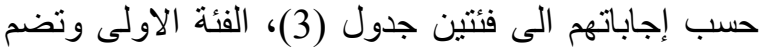

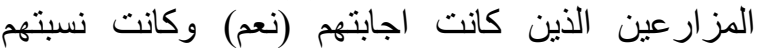
(40.28\%)، أما الفئة الثانية فتضم المزار (ارعين الذين كانت

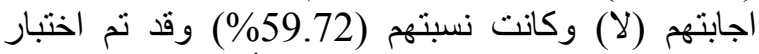
الفرضية الاحصائية التي تنص على أنه (لا توجد علاتئة ارتباط معنوية بين مستوى الاحتية لإنيات الإنية الارشادية

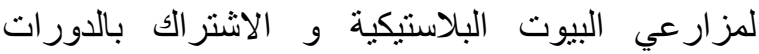

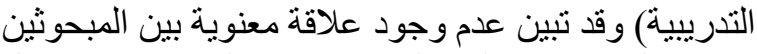

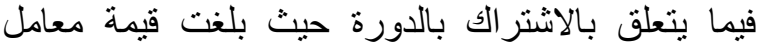
الارنباط (0.038) وقد يرجع السبب الى الى ان النسبة الاكبر

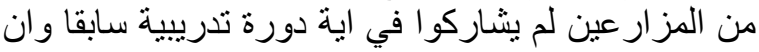
معظم الدورات التي اقيمت في المنطقة لم تكن متخصصة لترانة

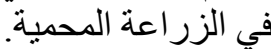
8- مصادر المعلومات:تم تصنيف المزار عين وفق مستوى

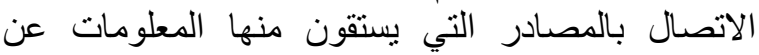

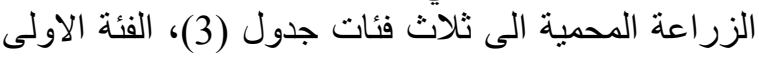

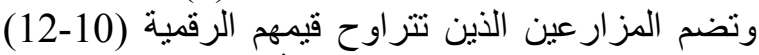

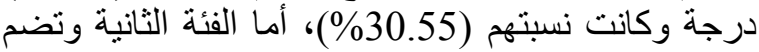
المزارعين الذين تتراوح قيمهم الرقمية (13-15) دانة) درجة وكانت نسبتهم (40.28\%)، أما الفئة الثالثة وتضنة المزارعين الذين تتراوح قيمهم الرقمية (16) (16أكثر) درجة وقانة

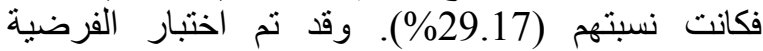

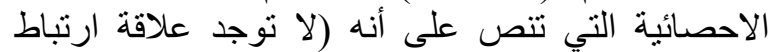

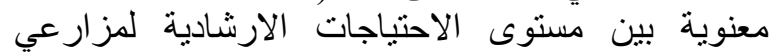

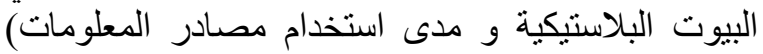

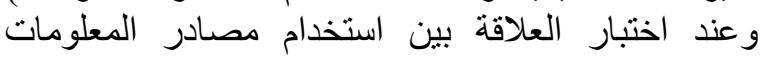
و الحاجة الى التدريب تبين عدم وجود علاقة ارتباطية بين

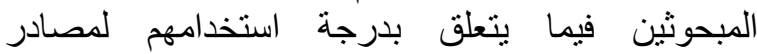
المعلومات حيث بلغت قيمة معامل بلئ الارتباط (0.038)

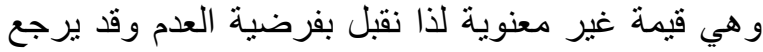

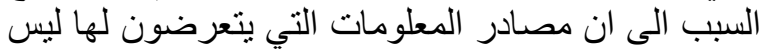
لها تأثنير في خبر اتهه.

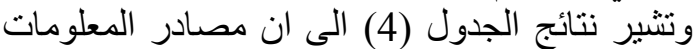

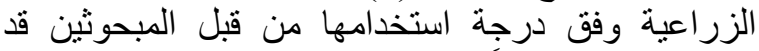
جاءت مرتبة تنازلياً على النحو الآتي: المرشد الزئة الزراعي

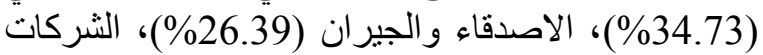
الزر اعية (12,5).
ارتباط معنوية بين مستوى الاحتياجات الارشادية لمزارعي البيوت البلاستيكية ومستوى التعليم)، وقد تلبين الإنين

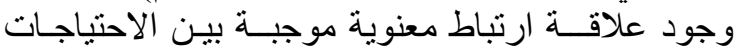

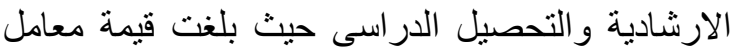

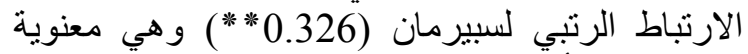

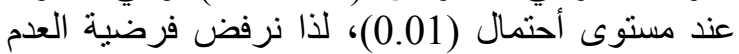

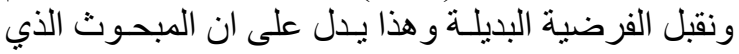

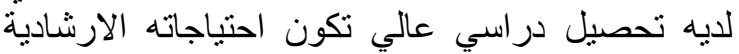

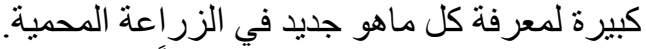

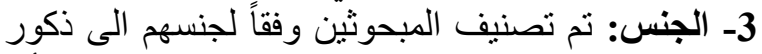

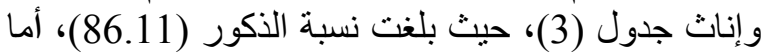

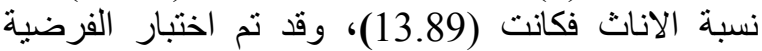

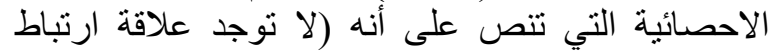

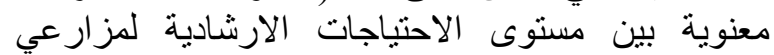

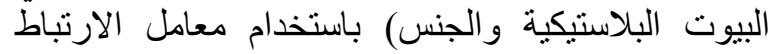

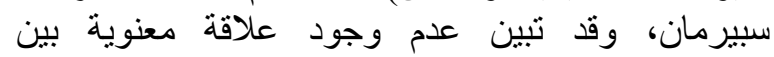

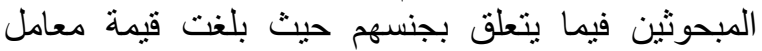
الارتباط (0.093)، لذا نقبل بفرضية الإنية العدم أي انه لايوجد

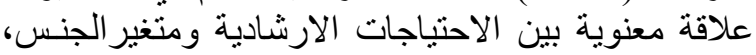

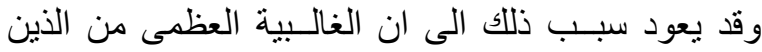
يقومون بالزر اعة في البيوت البلاستيكية هم ذكور.

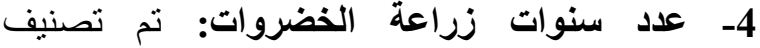

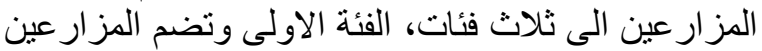

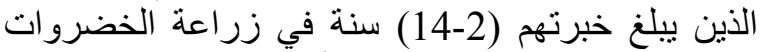

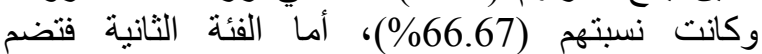

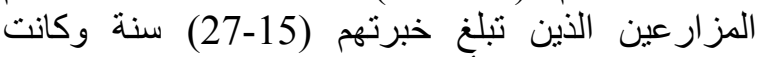

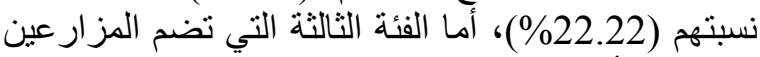

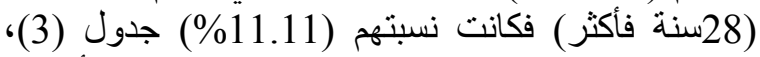
وقد نم اختبار الفرضية الاحصائية التي تنص على ألى أنه (لانية

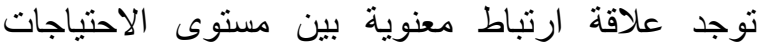

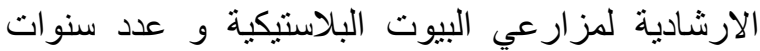

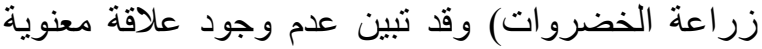

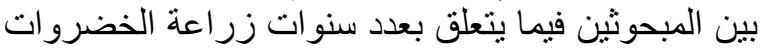

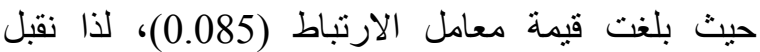

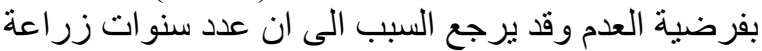
الخضروات لاتؤثر في الخبرة بالزراعة في الني البيوت

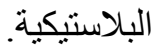

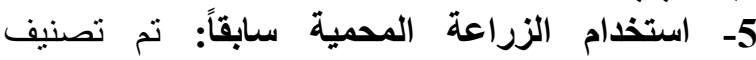

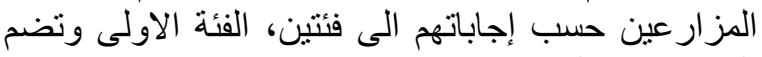

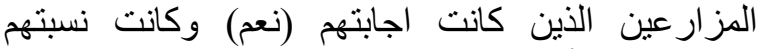

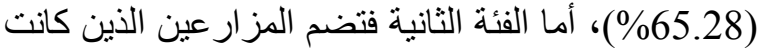

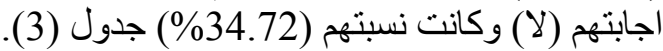

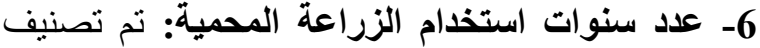

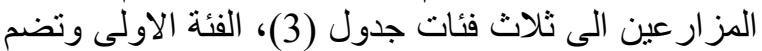

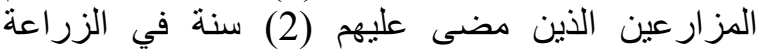

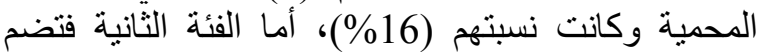

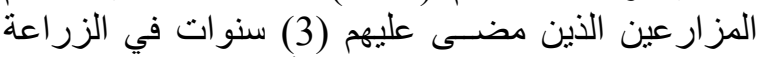

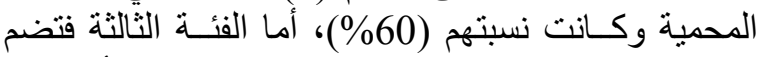

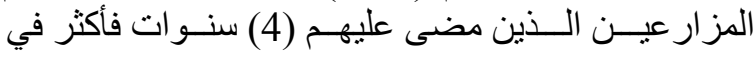


اختيار موقع البيوت المحمية) في نظر الاعتبار عند

اعداد بر امج تدرييية تخص البيت اليبوت البلاستيكية.

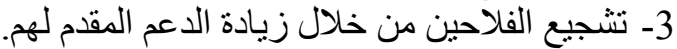

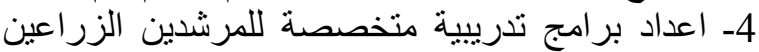
في المنطقة حول الزر اعة المحمية. 5- توجيه البر امج التلفزيونية والزاذاعية الزية الزراعية للتركيز اكثر على جو انب الزر اعة المحمية في المنطقة.

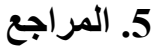

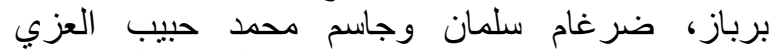
(2012)، كفاءة اداء مشاريع البيوت البلاستيكية

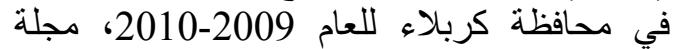

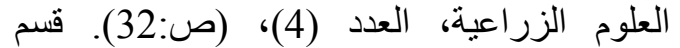

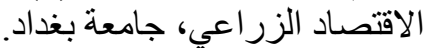

سداد، ساهر حسن (1993) نموذج نطبيقي لعملية نقل

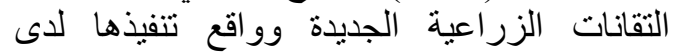

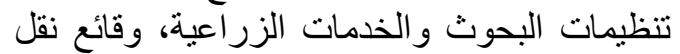

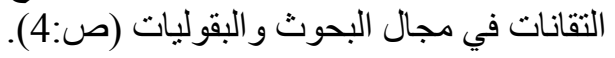

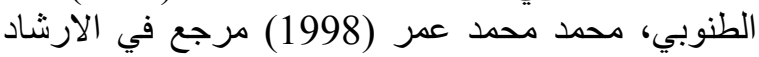
الزراعي، دار النهضة العربية.

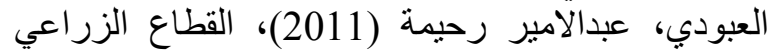

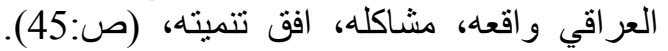

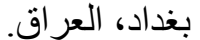

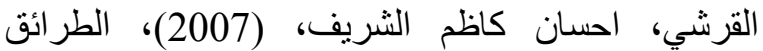

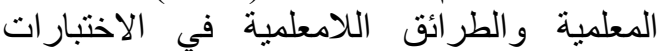

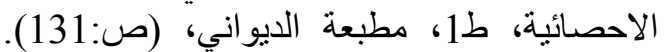

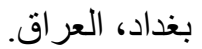

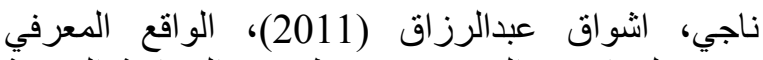

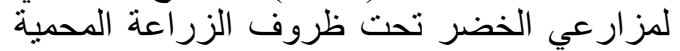

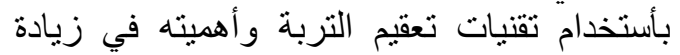

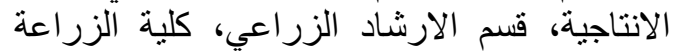

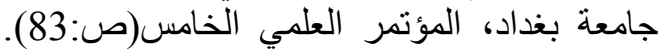
لكلية الزر اعة، جامعة تكريت.

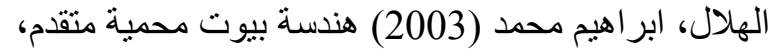
قسم الهندسة الزراعية، (ص: 17 17). كلية الاغذية لهنية والزر اعة، جامعة الملك سعود.
جدول رقم (4): توزيــع المبحوثين وفـق درجـة استخدامهم المصادر المعلومات الزراعية.

\begin{tabular}{|c|c|c|c|}
\hline المئوية & العدد & مصادر المعلومات الزراعية & $ت$ \\
\hline 34.73 & 25 & المرشد الزراعي & 1 \\
\hline 26.39 & 19 & الاصدقاء و الجيران & 2 \\
\hline 12.50 & 9 & الثركات الزر اعية الاهلية & 3 \\
\hline 11.11 & 8 & البر امج الزر اعية التلفزيونية & 4 \\
\hline 5.55 & 4 & البرامج الزر اعية الاذاعية & 5 \\
\hline 4.16 & 3 & النشرات الارشادية & 6 \\
\hline 2.78 & 2 & المؤسسات التعليمية & 7 \\
\hline 1.39 & 1 & محطات البحوث & 8 \\
\hline 1.39 & 1 & الصحف و المجلات & 9 \\
\hline$\% 100$ & 72 & المجموع & \\
\hline
\end{tabular}

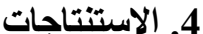

1- يتح ان المزارعين يعانون نقصاً في الاحتياجات

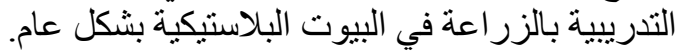
2- يتضح ان الغالبية العظمى من المبحوثين ينتمون اللى لئية الفئة العليا و الوسطى للحاجة للتدريب. 3- يتضح وجود علاقة ارتباطية معنوية بين الاحتياجات

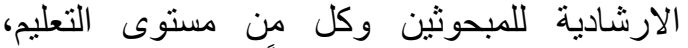
و واستخدام الزر اعة المحمية سابقاً. 4- يتضح عدم وجود علاقة ارتباطية معنوية بين الزين

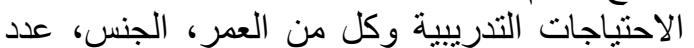

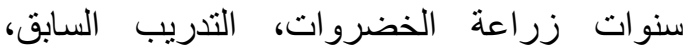

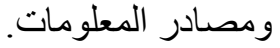

\section{التوصيات}

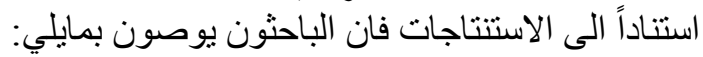

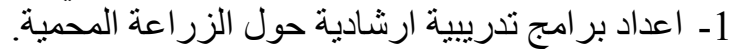

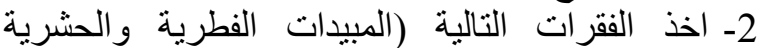

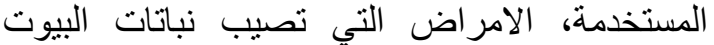
المحمية، المكافحة والوقاية داخل البيوت المحمية، 